Literatura y Lingüística $\mathrm{N}^{\circ} 25$

ISSN 0716-5811 / pp. 39-59

\title{
El poshumanismo apocalíptico en la novela negra argentina contemporánea: Ciudad santa y $77^{*}$
}

\author{
Osvaldo Di Paolo**
}

\section{Resumen}

El fin del mundo es un arquetipo milenario, el cual se ha acentuado en tiempos recientes. La obsesión actual con la destrucción del planeta también se evidencia en el género negro. Gran parte de la novela negra hispanoamericana del siglo XXI presenta una visión poshumanista y apocalíptica que revela la descentralización del individuo y manifiesta el caos, el miedo y el enfrentamiento de fuerzas opuestas que conllevan a la destrucción del género humano. Para demostrar mi tesis analizo dos novelas argentinas y ganadoras del Premio Hammett: Ciudad santa (2010) de Guillermo Orsi y 77 (2009) de Guillermo Saccomanno. De cada texto, presento un resumen general, extraigo las particularidades estructurales de la novela negra y revelo la tendencia poshumanista y apocalíptica inherente a los mismos, junto con sus implicaciones sociales.

Palabras clave: novela negra, apocalipsis, poshumanismo

\section{Apocalyptic Posthumanism in Contemporary Argentine Hardboiled: Ciudad santa and 77}

\begin{abstract}
The end of the world is a millennial archetype, which has become quite popular in recent times. The current obsession with the destruction of the planet is also present in hard-boiled literature. A great number of the XXI Century hard-boiled genre presents a posthumanist and apocalyptic view that reveals the decentralization of man and manifests chaos, fear, and the clash of opposite forces that lead to the destruction of the human race. In order to prove my thesis, I analyze two argentine novels, winners of the Hammett award,: Ciudad santa (2010) by Guillermo Orsi and 77 (2009) by Guillermo Saccomanno. From each text, I present a summary of the story, draw the structural characteristics of the hard-boiled, and reveal the posthuman and apocalyptic tendencies in the novels, along with the social implications they convey.
\end{abstract}

Key words: hard-boiled, apocalypse, posthumanism

Recibido: 11-11-2011 Aceptado: 29-12-2011

* Este artículo es parte de la investigación y del libro titulados "Gemidos y explosiones apocalípticas poshumanas: la novela negra y de ciencia ficción hispana en el siglo XXI”, el cual saldrá publicado por Teseo en agosto de 2013.

** Doctor en Letras. Austin Peay State University. dipaoloo@apsu.edu 
El poshumanismo apocalíptico en la novela negra argentina contemporánea: Ciudad santa y 77 / Osvaldo Di Paolo

\section{Introducción}

La destrucción del mundo o "el fin del mundo" es un arquetipo milenario que ha estado presente en el imaginario humano desde el año 1500 a.C., con las profecías de Zoroastro. Este profeta iraní ya hablaba de un fin cercano con el propósito de reemplazar al mundo imperfecto de ese entonces. ${ }^{1} \mathrm{~A}$ través de los siglos, desgracias y catástrofes como la peste negra de 1348, la guerra de los 100 años entre Francia e Inglaterra y la conquista de Constantinopla en 1453 fueron interpretadas como sucesos apocalípticos (Carbajal 90). Hasta Cristóbal Colón escribió "en el año de 1500 que el fin del mundo llegaría como mucho al cabo de 150 años" y Lutero afirmó: "hemos llegado al tiempo del caballo macilento del Apocalipsis, este mundo no durará más de un centenar de años" (Delumeau 118). En tiempos más recientes, esta preocupación apocalíptica se manifiesta a través de la secta Heaven's Gate ${ }^{2}$, la Orden del Templo Solar ${ }^{3}$, el movimiento Religioso de Uganda ${ }^{4}$, las predicciones de Harold Camping, pastor evangelista y locutor de radio de Oakland, California, que estableció la fecha de 21 de mayo de 2011, y, por supuesto, el famoso pronóstico maya de que el fin del mundo vendrá en 2012.5

1 En Countdown to Apocalypse: A Scientific Exploration of the End of the World, Paul Halpern indica que "unlike devotees of cyclical time-based faiths, Zoroastrians believe in a 'last judgment,' in which good is rewarded, evil is punished, and history draws to a close. The principles of Zarathustra do not allow for evil to return again after the time of judgment; therefore, from that point on, new cycles of existence would be impossible. Once the force of asha reigns triumphant, the human drama is over" (55).

2 Heaven's Gate estaba conformado por un grupo de personas que vivían juntos en un rancho en Santa Fe, una afluente comunidad de San Diego. En "Heaven's Gate: The End?", Wendy Gale Robinson explica que "on March 26, 1997, the bodies of 21 women and 18 men, ranging in age from 26-72, were discovered in various stages of decomposition. Several days before, they had ingested applesauce or pudding laced with barbiturates and a shot of vodka, and they had submitted to suffocation from plastic bags placed over their heads. They were identically dressed in unisex black shirts, pants, and Nikes, and had purple shrouds placed across their faces. Many of the men had been castrated. Nevertheless still frustrated with their bodies, they chose to leave their 'earthly containers' behind in San Diego to join aliens who would take them to the Next Level with a newly embodied life." (1).

3 La Orden del Templo Solar es una secta fundada por el Dr. Luc Jouret y responsable de suicidios colectivos. El primero se produjo "el 4 de octubre de 1994 en Cheiry y Salvan, dos idílicas aldeas de Suiza. Murieron 48 personas calcinadas. El 23 de diciembre de 1995 otros 16 cuerpos fueron encontrados carbonizados, entre ellos tres niños, en un bosque de los Alpes franceses, en la región de Grenoble" (www.victimasectas.com/Terrorismo/ OrdenTemplo Solar. html).

4 El caso de Uganda es una tragedia que ocurrió en 2000, donde más de mil personas llevaron a cabo un suicidio colectivo. Es considerado el más grande de la historia contemporánea (Erderly 120).

5 Para una visión más completa sobre el tema del apocalipsis, ver "Apocalipsis: la angustia del fin del mundo" de Emilio Carbajal; ver bibliografía.

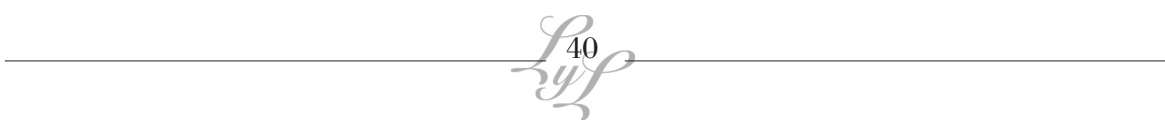


Esta obsesión actual con el fin del mundo también se evidencia en la novela negra contemporánea. ${ }^{6}$ Tanto los críticos literarios como los escritores y lectores del género coinciden en que la vertiente negra es la mejor manera de reflejar los problemas que se materializan en la sociedad actual, ya sean de violencia, corrupción, género sexual, socioeconómicos o políticos, para mencionar algunos. Para el escritor Juan Martini, es imposible no detectar los conflictos que "acechan y perturban al hombre de hoy: al hombre que vive y padece un ordenamiento social regido por el despotismo de los intereses económicos y por la violencia como expresión más obvia -y más dramática- de las luchas por el poder en cualquiera de sus formas" (citado en Laforgue 222). En su esencia, la novela negra es una literatura que da testimonio de la desesperación e incertidumbre que reinan en el mundo.

Si bien todo esto es innegable, es necesario seguir indagando por qué se escriben y leen asiduamente estos textos de la vertiente negra y qué temáticas manifiestan. En mi libro Cadáveres en el armario: el policial palimpséstico en la literatura argentina contemporánea, ya he señalado que leemos novelas policiales porque: (1) nos permiten ver el comportamiento de los demás ciudadanos y nos dan una mejor idea de cómo manejarnos en el entorno social inmediato; (2) sirven de entretenimiento; (3) son una denuncia cruda y una forma de reflexionar sobre los malestares existentes en los países hispanos y en el mundo entero; (4) es fácil reconocer lo que viven los personajes, ya que son situaciones compartidas e identificables. Una razón más profunda, pero concurrente con las anteriores, reposaría en que la novela negra hispanoamericana del siglo XXI es una literatura poshumanista y apocalíptica que revela la descentralización del individuo y manifiesta el caos, el miedo y el enfrentamiento de fuerzas opuestas que conllevan a la destrucción del género humano.

Por poshumanismo, en el caso específico de la novela negra propiamente dicha, me refiero a la pérdida de la capacidad del individuo de utilizar la razón para solucionar problemas sociales y culturales, llevándolo

6 A partir de fines de 1950 en adelante, el auge del género negro en los países hispanos es una realidad indiscutible. Durante esta época se produce una paulatina transformación de la novela clásica tradicional -solución racional de un enigma por parte de un detective- en novela negra, ya que se incorpora una aguda crítica social para denunciar ciertos aspectos de la sociedad actual y se expresa una desesperanza en un futuro mejor, donde todo es irresoluble e irreversible. Quizás los pioneros y más conocidos por promover esta evolución en el mundo hispanohablante son el argentino Rodolfo Walsh con Operación masacre (1957), el mexicano Rafael Bernal con El complot mongol (1969) y el español Eduardo Mendoza con La verdad sobre el caso Savolta (1975). 
El poshumanismo apocalíptico en la novela negra argentina contemporánea: Ciudad santa y 77 / Osvaldo Di Paolo

a depender de dinamismos inadecuados que lo excluyen de una posición privilegiada. ${ }^{7}$ Por apocalipsis ${ }^{8}$ aludo a la revelación y reconocimiento de la destrucción del mundo tal cual lo conocemos, incorporando una visión laica y cristiana. ${ }^{9}$ Para demostrar mi tesis, analizo dos novelas argentinas y ganadoras del Premio Hammett: Ciudad santa (2010) de Guillermo Orsi y 77 (2009) de Guillermo Saccomanno. De cada texto, presento un resumen general, extraigo las particulares estructurales de la novela negra y revelo la tendencia poshumanista y apocalíptica inherente al mismo, junto con sus implicaciones sociales.

\section{Ciudad santa: una ciudad ideal dentro de otra "real" y corrompida}

La historia de Ciudad santa de Guillermo Orsi transcurre en la ciudad de Buenos Aires y presenta una gama de personajes de distintos estratos sociales. La novela puede leerse como un todo, buscando conectar los hechos individuales de cada personaje o como historias aisladas, únicas e individuales de seres perdidos en un mundo decrépito. Es un collage conformado por la vida de estos protagonistas y por distintas voces que se unen en una para aterrar al lector con una prosa macabra y una sucesión de imágenes desmoralizantes. Verónica Beruti es una abogada que enviudó durante la transición a la democracia después de la dictadura militar de 1976-1983. Su esposo era policía y fue asesinado por entregar información a la justicia, para implicar a ciertos compañeros suyos en el genocidio de la represión militar. A su vez, Verónica es la abogada de Ana Torrente, reina de belleza boliviana que llega a Buenos Aires con

7 En The Routledge Companion to Literature and Science, Bruce Clarke incluye "Posthumanism" de Neil Badmington. Según Badmington, el poshumanismo "emerges from a recognition that Man is not the privileged and protective center, because humans are no longer -and perhaps never were- utterly distinct from animals, machines, and other forms of the inhuman" (374).

8 Para el teólogo John McArthur, "Apokalupsis (revelación) tiene el "significado de "hacerse visible" y es una historia de primera página del futuro del mundo, escrita por alguien que la ha visto toda" (25).

9 Por apocalipsis cristiano, me refiero a la oposición de San Agustín al milenarismo que veía al nacimiento de Cristo como el comienzo de los mil años de su reino, al que le seguían el juicio final y el arribo de la ciudad celestial. San Agustín aboga por una lectura simbólica del texto bíblico (Carbajal 88). El apocalipsis laico hace referencia a la concepción secular del siglo XVIII, a la Ilustración, y a la Revolución Francesa. Por ejemplo, en el siglo XVIII se critica la creencia literal de la profecía de los textos bíblicos y su realización, cuestionando la autoridad de la iglesia y de las monarquías. A su vez, esta idea del apocalipsis secular continúa con el progreso acumulativo de la civilización moderna, la crisis de valores y el terror de las Guerras Mundiales, hasta impregnarse en una visión posmoderna que, al negarse a dar respuestas determinantes, provoca "estados anímicos de melancolía" y desilusión, sin esperanzas de futuro (96).

12 
la ilusión de alejarse de la decadencia tercermundista de su país, pero termina enamorando policías y trepando por poder en el mundo de la droga. Ana es seguida por su hermano, Jaguar, un insensato que decapita a las víctimas que asesina Ana y que se refugia en Tierra Santa, un parque temático religioso en medio de la "santa" ciudad de Buenos Aires. Otro personaje es el paraguayo Pecagoya, amante ocasional de Verónica y guía turístico para un crucero que, por averías, tuvo que parar en Buenos Aires. Es un hombre sin escrúpulos que satisface todas las necesidades de sus pasajeros, vendiéndoles droga y entregándose sexualmente a cualquiera de ellos -hombres y mujeres- por dinero.

Dentro del grupo de policías federales y bonaerenses que aparecen en la trama se destacan dos: Oso Berlusconi y el subinspector Walter Carroza. El primero es amante de Miss Bolivia y se jacta de haber participado en el asesinato y tortura de ciudadanos argentinos durante la última dictadura militar. Además, es responsable del asesinato y secuestro de cuatro parejas de millonarios extranjeros que estaban a bordo del averiado crucero Queens of Storms, de los cuales tres son directivos de multinacionales y uno, Osmar Arredri, es el jefe de un poderoso cartel de Medellín. El segundo policía, también amante de la boliviana, jamás participó del genocidio a fines de la década del 70 , pero, al intervenir en la investigación del secuestro de los extranjeros, hace un arreglo con Sirena Mondragón, la mujer del traficante. Para no terminar asesinada como Arredri, ella jura darles millones de dólares a cambio de su libertad a Carroza, Miss Bolivia y al Tío, jefe de un cartel de drogas argentino.

Estas situaciones se entretejen de manera que el texto se amolde a la modalidad discursiva de la novela negra, especialmente porque, a pesar de que la producción artística siempre presupone una mirada subjetiva, la vertiente negra conserva rigurosamente una crítica de la sociedad o de la realidad circundante, lo que ha llevado a la crítica literaria a llamarla también realismo crítico o realismo crudo (Lebrato Martínez 130). El sujeto de la enunciación es un narrador omnisciente, quien no participa en la historia, pero que conoce las motivaciones sicológicas de los personajes y las relata en tercera persona. Por ejemplo, el narrador comenta que Pacogoya se acuesta con hombres "cuando está muy solo, como hoy, muy desconcertado, como recién nacido en un mundo devastado por alguna catástrofe nuclear" (Orsi 62). A diferencia de muchas novelas del género negro, que presentan un detective que paulatinamente acumula información y finalmente logra descubrir -siguiendo pistas o de forma accidental-o reconstruir lo pasado, el narrador presenta a diferentes po- 
El poshumanismo apocalíptico en la novela negra argentina contemporánea: Ciudad santa y 77 / Osvaldo Di Paolo

licías que no investigan, sino que participan en la corrupción del mundo de la droga. De cualquier forma, el narrador no se detiene en un crimen o personaje en particular, sino que presenta una gama de situaciones abrumadoras - prostitución, negocios sucios, asesinatos, secuestro, entre otras- para componer un collage del desaliento que reside en una Buenos Aires globalizada, venida a menos y llena de turistas que, al ser secuestrados y sacrificados, llegan a conocer el peligro que reina en la ciudad.

El tiempo del relato es principalmente lineal y los escasos saltos al pasado son para mostrar que la desesperación e impotencia de los personajes no es reciente, ya que vienen de la historia de la nación misma y van oscureciendo la vida de estos porteños. Se menciona la dictadura militar, reflejando la patología de aquellos que perdieron a seres queridos (como es el caso de la abogada viuda) y la actual sicopatía de torturadores y homicidas, como Oso Berlusconi, quienes nunca fueron castigados y siguen dañando a la sociedad en el mundo de la droga y de la corrupción política. El espacio del relato es la ciudad, típico escenario de la vertiente negra, la cual alberga todas las relaciones del mundo capitalista actual (Lefebvre 43). El desplazamiento y las interacciones citadinas son motivados por la obtención de poderes económicos legales -industria del turismo- e ilegales -droga, prostitución y secuestros.

La variedad de personajes citadinos que confluyen en Buenos Aires actúa de un modo poshumanista. Según Neil Badmington, el arquitecto del humanismo es Descartes, quien en Discurso del método señala que la razón es "the only thing that makes us men and distinguishes us from the beasts" (36), marcando una diferencia absoluta entre lo humano y lo no-humano (44)..$^{10}$ Una metáfora representativa de ser no-humano aparece en la novela en un comentario sobre las víctimas del Jaguar que llegan incompletas a la morgue, ya que les faltan las cabezas. El narrador extradiegético explica que algunas de las cabezas aparecen días más tarde, pero "las que llegan están vacías, huecas como las de tantos que andan por la vida fingiendo ser seres humanos" (Orsi 160). Pareciera que todos los personajes carecen de juicio. Sus cabezas sólo están llenas de codicia y poder, incitándolos al crimen y sin pensar en las consecuencias negativas que esto acarrea. El inspector Carroza dice que el agente Oso Berlusconi es "un policía retirado, basura dictatorial que sin embargo protegen los políticos, nadie lo acusó nunca de nada pese a que hubo más de un testimonio en su contra, un carnicero eficiente para armar operaciones

10 Ver "Approaching Posthumanism" de Neil Badmington.

$+44$


clandestinas" (179). Las fuerzas de la ley trabajan para los políticos que, a su vez, se encuentran implicados en el tráfico de drogas. Carroza le comenta a su sicólogo que "el concejal Viruela conserva con mano de hierro el negocio de la droga" (10) y que "los diputados provinciales y los "jerarcas policiales...controlan la droga y prostitución" (34).

Es un reflejo de la sociedad argentina contemporánea, la cual evidencia un aumento del tráfico, producción y consumo de droga. En una entrevista con el diario La Nación, publicada en marzo de 2001, el embajador colombiano en la Argentina, Jaime Bermúdez, explica que la Argentina sigue el mismo camino de México y Colombia, ya que

es un país de arribo y traslado de cocaína, como quedó claro en el reciente caso del avión cargado con una tonelada de esa droga, que aterrizó en Barcelona. La droga la habría proporcionado, según la investigación española, un importante cartel colombiano. Tampoco eso debería tranquilizar a nadie. México cumplió el mismo papel durante muchos años, porque el país azteca tiene, además, una puerta directa abierta con Estados Unidos, el mayor mercado de consumo del mundo. Pero sucedió que un día los delincuentes mexicanos se dieron cuenta de que el negocio podía ser de ellos. Decidieron dejar de hacer el trabajo menor de transportistas de la droga colombiana; formaron sus propios carteles y ahora rivalizan entre ellos por el grado de crueldad a la hora de torturar y matar. (Morales Solá 1)

Según el narrador de la novela y de acuerdo al comentario de los protagonistas, son políticos influyentes del país los que manejan el mercado de la droga con la complicidad de la policía local y federal. Esta dinámica coincide con la entrevista que Christian Sanz le hace a Abel Reynoso, ex jefe de la Dirección Antidrogas de Estado (DEA), incorporada en Poli Armentaro: un crimen perfecto (2003). Una de las preguntas que le hace Sanz es cómo funciona el narcotráfico en la Argentina y Reynoso le responde señalando que en el negocio de la droga se necesita una rama de procesamiento, transporte, tratamiento químico y el lavado de dinero. Para el entrevistado, el único que no predomina en la Argentina es el proceso de fabricación de la droga. Es un país de tránsito, pero eso no es poca cosa porque "el tránsito sólo es posible cuando se pone dinero. No es gratis. Tránsito significa plata, es la parte más peligrosa del proceso. No hay tránsito sin corrupción" (51).

En Ciudad santa se evidencia la deshumanización de los personajes, quienes, en vez de optar por un razonamiento lógico en busca de un 
El poshumanismo apocalíptico en la novela negra argentina contemporánea: Ciudad santa y 77 / Osvaldo Di Paolo

bienestar común, eligen una búsqueda de satisfacción individual, objetivo por el que son capaces de cualquier cosa. Con tal de mantener una posición privilegiada en el mundo de la droga, todos asesinan, engañan y/o son traicionados tarde o temprano. Esto es todo lo contrario de lo que promueve el humanismo. En "Approaching Posthumanism", Badmington explica que "reason belongs solely to the human and, as such, serves to unite the human race" (4). Para el humanismo, aunque tengamos distintos tipos de cuerpos, esta racionalidad compartida que yace en la mente de todos los seres humanos también implicaría que somos todos iguales. El ideal humanista se ha desmoronado porque no existe hermandad alguna, solamente prevalece la desunión y la desigualdad en la novela de Orsi.

Prevalece una diferenciación racial y de poder en Ciudad santa y hasta Miss Bolivia piensa que su tierra es "un país de indios en pie de guerra, una tribu de apunados. Creen que Viracocha vendrá a salvarlos, son peores que los árabes" (Orsi 17). Lo que es más, Chucho, el chofer de Verónica, la abogada, le advierte que los bolivianos son "mugrientos y ladrones...no se fíe de un bolita, doctora. No habría que dejarlos entrar en la Argentina, hacer lo que hacen los gallegos con los negros del África... son traicioneros, son indios, qué va a esperar" (80). Chucho no solamente discrimina rotundamente al boliviano sino al indígena en general, incluso al del noroeste argentino. Al comentarle a Verónica que su hija estaba de novia con un muchacho que parecía boliviano pero "ni siquiera era bolita, era de Jujuy, pero todos los collas son iguales" (81). Chucho representa al sector que discrimina al boliviano y vocaliza este pensamiento colectivo subyacente en gran parte de la población. Según un informe de la Unicef publicado el 16 de julio de 2011 por el diario El Día, "siete de cada diez adolescentes [bolivianos] fueron testigos de alguna forma de discriminación y cuatro de cada diez la sufrieron en carne propia" (1). ${ }^{11}$

La visión poshumanista -sinrazón y desunión- en el texto de Orsi se complementa con una impresión apocalíptica de Buenos Aires. En Lamb's Supper: The Mass as Heaven on Earth, Scott Hahn explica que, en un sentido literal, el Apocalipsis de la Biblia se refiere a la caída de la ciudad de Jerusalén y la destrucción del Templo en 70 después de Cristo

11 Se encuestaron alrededor de 900 adolescentes de las provincias de Buenos Aires, San Juan, Salta, Mendoza, Córdoba, Santa Fe y Jujuy y ciudad de Buenos Aires. Según el reporte, "los lugares con mayores situaciones de discriminación para los encuestados son la escuela (67\%), la calle (18\%), lugares bailables (9\%), en entrevistas laborales (3\%) y en los estadios (1\%). El 63\% de los encuestados declaró que en el fútbol se discrimina, entre otras cosas, por cantitos como "iay! Qué vergüenza/ dio ver en la Argentina/ los negros de la villa/ saliendo a festejar. / Por eso yo/ te pediré/ cuando salgas campeón/ váyanse a dar la vuelta/ a Bolivia o a Paraguay" (1).

(4) 
(93). Esta sería una interpretación preterista del texto, proveniente del Latín praeter o pretérito y reflejaría acontecimientos que estaban ocurriendo o acababan de ocurrir en un pasado reciente, presentando una visión no profética (Edinger 8). El texto, supuestamente escrito por el apóstol Juan, describe la corrupción de la antigua Jerusalén y la compara con una prostituta "drunk with the blood of the saints and the blood of the martyrs of Jesus" (Apocalipsis 17:6). ${ }^{12}$ Además, cabe recordar que las autoridades de Jerusalén son las que sentencian a Cristo y la ciudad era un centro de persecución de la primera generación de cristianos (Actas 6:8-14, 7:57-60, 8:1-3). El apóstol Juan llama alegóricamente a Jerusalén Sodoma y Egipto por ser centros de oposición al plan divino. En "Apocalypse Then!", Scott Hahn agrega que "Sodom stood in the way of God's covenant plan with Abraham; Egypt stood in the way of His covenant plan for Moses and Israel. Now, it's Jerusalem's turn to oppose God, as its leaders persecute the Apostles and the Church" (95).

Esta mirada preterista del Apocalipsis es incorporada en Ciudad santa con una visión idealista o simbólica. Buenos Aires se ha convertido en la Jerusalén del pasado, en una ciudad prostituida que merece ser exterminada. En el texto, el narrador dice que Pacagoya, el guía turístico, se despierta con la imagen de Buenos Aires como si fuera la ciudad santa de Jerusalén (73), y el inspector Carroza, al charlar con otro policía sobre los cadáveres decapitados, señala que "Buenos Aires es, hoy más que nunca, ciudad santa" (152). Ambos, de manera irónica, se están refiriendo a la Jerusalén que merece ser destruida. El texto de Orsi es una sucesión de imágenes y acontecimientos desesperantes y aberrantes. Para Carroza la ciudad anuncia cadáveres y su radio policial le informa lo que está ocurriendo: "masculino con herida profunda de arma blanca sobre calle Cuzco, femenino descuartizado en terraplenes de ferrocarril Sarmiento...gresca entre fieles de San Cayetano" y "masculino joven malherido, homicidio en riña, femenino violada y arrojada en zanja sin signos vitales" (144). También, piensa en las discotecas porteñas que se "llenan de bailarines y las guardias de los hospitales, de drogones en shock y heridos de bala y arma blanca" (130).

De la misma forma, el narrador describe a la feria de Buenos Aires "como un mercado persa del contrabando y el robo a cielo abierto... Buenos Aires es una selva sin tarzanes; un jardín artificial en el que las rosas y los jazmines son de plástico, donde los ricos viven en barrios

12 Otros textos del Viejo Testamento también describen a Jerusalén como una prostituta. Ver Ezequiel 16:2-6-3 y 23:2-49, Jeremías 2:20 y 3:3 e Isaías 1:21. 
El poshumanismo apocalíptico en la novela negra argentina contemporánea: Ciudad santa y 77 / Osvaldo Di Paolo

construidos sobre los escombros o sobre los muertos" $(27,32)$. Todos los personajes tienen una visión terrorífica de la ciudad, incluso Miss Bolivia se desilusiona al ver que Buenos Aires no es la París del Sur como ella pensaba, en la cual hasta los taxistas hablaban francés, y se dice a sí misma: "te mintieron... Buenos Aires está tan llena de negros como cualquier ciudad en ruinas de Bolivia o del Perú" (38). La violencia, el mundo de la droga, la pobreza, la falta de escrúpulos, la corrupción y los deseos desmedidos prevalecen y destruyen toda lógica hermandad.

La desesperante ciudad de Buenos Aires se contrapone con otra ciudad santa que se encuentra dentro de la misma. Es el parque temático Tierra Santa ubicado cerca del aeropuerto. Para el narrador, esa es la ciudad santa, pero es irreal e inalcanzable. Es una "Jerusalén de pasta de cartón" (7). Es en esta ciudad artificial donde vive el Jaguar, quien decapita cadáveres. El Jaguar construye con esos cráneos su propio altar en busca de resurrección y vida eterna. El descuartizador quiere construir su propio monte Calvario, el Gólgota que significa "monte de las calaveras" (300). Pareciera que el Jaguar reconoce que Buenos Aires es Sodoma, Egipto, la Jerusalén maldecida y plagada de desgracia. No quiere vivir en ella porque ahí ya no hay salvación. Debe buscar la vida eterna en una nueva Jerusalén, la Jerusalén que emerge al final del Apocalipsis. Aquí se revela una interpretación futurista del texto bíblico.

En "The Grand Final Catastrophe", George Edinger explica que una de las posibles interpretaciones de Apocalipsis es "the futurist interpretation... the text of Revelation refers to events around the Return of Christ, coming sometime in the future" (9). Buenos Aires está perdida, ya no tiene salvación, su completa destrucción se avecina. El Jaguar lo sabe y se refugia en Tierra Santa. También el inspector Carroza lo intuye. Al conversar con otro policía, quien cree que el Jaguar está muerto, Carroza le responde "nadie muere para siempre, Escocés. Mira Jesús, qué sorpresa les dio a los judíos de Galilea" (152). Este comentario avecina el apocalipsis, la destrucción del mundo tal como lo conocemos. Menciona claramente la posibilidad de la segunda venida de Cristo, una sorpresa para muchos, como dice el inspector Carroza. A su vez, abre la esperanza de que, en este caso, Buenos Aires se regenere de sus propias ruinas y se convierta en la ciudad santa y celestial, en la Jerusalén que se describe en la parte final del Apocalipsis. ${ }^{13}$

13 La cuarta parte del Apocalipsis revela que el narrador vio emerger una nueva ciudad como símbolo de una flamante iglesia: "I also saw the holy city, a new Jerusalem, coming down out of heaven from God, prepared as a bride adorned for her husband (21:4).

18




\section{77: genocidio, deshumanización colectiva y la catástrofe del "Gran daño"}

La novela 77 de Guillermo Saccomanno recrea el tema de la dictadura militar argentina (1976-1983), el cual también se vio presente en Ciudad santa de Orsi, y en ella se relata la vida del profesor Gómez durante el año más peligroso del terrorismo de Estado (1977). Ese mismo año, y en busca de entender el caos que lo rodea, Gómez hace una consulta privada con un astrólogo-vidente-mentalista llamado el "Doktor Joseph Lutz" e interesado en el ocultismo y las profecías de Krumm Heller (18761949). ${ }^{14}$ El profesor continúa su investigación espiritual, discurriendo sobre el I Ching y la astrología hermética. A su vez, un vecino hace brujerías quemando cabellos, y en el picaporte de su puerta, el profesor encuentra un sapo muerto. El profesor es homosexual, y mientras levanta taxiboys, es testigo de los secuestros, la violencia y el terror que invaden las calles de una Buenos Aires nocturna. Tampoco sus estudiantes están a salvo. Su alumno Esteban es arrestado por los militares durante su clase de literatura argentina.

Durante una pelea con un novio casual, el profesor Gómez es detenido. Es ahí donde conoce a Walter, un policía que tiene relaciones sexuales con él y que trabaja para la dictadura. Gómez trata de conseguir información sobre el paradero de su alumno Esteban. Al no aparecer, Azucena, la madre del muchacho, le hace brujerías al General Videla, presidente de la junta militar. En la vida del profesor reaparece Martín, un adolescente guerrillero e hijo de Delia, una amiga suya que había sido asesinada en la dictadura del 55. El profesor se compromete a llevar una carta, enviada por Martín a los guerrilleros de la ciudad de Rosario. A su regreso, la Colo, embarazada y comprometida políticamente como su novio Martín, se va a vivir a la casa del profesor, porque el muchacho debe seguir luchando contra el gobierno de facto. A través de una nota periodística, Gómez se entera de que Martín fue asesinado por las fuerzas militares. Unos días más tarde, el diario también anuncia la "heroica" muerte de Walter, en su lucha contra la guerrilla. Después de narrar los horrendos hechos de 1977, el profesor finaliza su relato dando datos sobre el ajusticiamiento que sufrieron varios individuos durante

14 En the Unknown God: W. T. Smith and the Thelemites, Martin Starr observa que Krumm Heller es conocido por el nombre místico de Huiracocha. Heller era el representante de la "German Sovereign Sanctuary of the Ancient and Primitive Rite", conocido por su libro Logos Mantram Magia de 1930 (76). 
El poshumanismo apocalíptico en la novela negra argentina contemporánea: Ciudad santa y 77 / Osvaldo Di Paolo

el período democrático por haber estado involucrados en la tortura y el exterminio de ciudadanos durante la dictadura.

La novela de Saccomanno carece de un detective propiamente dicho. El profesor Gómez ni siquiera investiga sobre la desaparición de sus estudiantes. Tan sólo le pregunta a su amante, Walter, si sabe algo sobre el paradero de estos muchachos y, en realidad, no logra sacar datos concretos. Lo que sí hace Gómez es relatar la represión y el miedo que ve en sus nocturnas escapadas sexuales. Por ejemplo, al agarrarse una borrachera, el narrador cuenta que lo "despabiló la calle. Una sirena, corridas, gritos. De jóvenes, los gritos. Disparos. ... unos Falcon se cargaban dos chicos y una chica. Un chico, el estómago ensangrentado, más muerto que vivo, se arrastraba contra la persiana de una panadería... a quemarropa, lo remató. Los autos arrancaron. El chico quedó tirado" (Saccomanno 90) ${ }^{15}$. El profesor es un flâneur que camina la ciudad, siendo así testigo de las atrocidades del gobierno. Tampoco se construye la narración alrededor de un criminal específico. Aunque el amante de Gómez es el asesino más prominente, nunca se describen los asesinatos que este comete. Una noche, Walter, al desnudarse, saca su pistola y le pregunta a Gómez si quiere agarrarla. Al mismo tiempo, le confiesa: "si supieras las cosas que hago". Su amante le responde "prefiero no enterarme" (60).

A pesar de no haber un detective o un asesino concreto, ni una investigación formal o casual de un crimen específico, la novela apunta a mostrar el interminable número de torturas, secuestros y asesinatos que presencia el profesor durante 1977. Lo que sí se encuentra presente es el sentido de justicia y la aplicación efectiva de la ley, elemento típico de la novela detectivesca clásica y poco frecuente en la vertiente negra. Después de presentar los abusos cometidos por el gobierno argentino durante todo un año, el narrador señala que, durante los juicios que se le hicieron a los comandantes, su colega Iturbide, profesor de anatomía, "fue acusado de participar como médico en las sesiones de tortura de un chupadero. Sus víctimas lo identificaron como el médico que respondía al apodo de Doctor Menguele". Asimismo, Gómez menciona las leyes de obediencia debida y de punto final que interfieren con el deseo de justicia. ${ }^{16}$ Según el narrador, pareciera que Iturbide salió de la cárcel,

15 Los Ford Falcon eran los autos que conducían la policía y se utilizaban para secuestrar y transportar a los presuntos guerrilleros.

16 La ley de obediencia debida fue aprobada durante el gobierno democrático de Raúl Alfonsín, y vigente hasta 2004, determinaba que aquellos militares, por debajo del grado de coronel, que

$+20$


beneficiado por estas medidas legales; al mismo tiempo, se mencionan los "escraches" que le hacen los militantes de H.I.J.O.S. a Iturbide, lo cual indica que la memoria se mantiene viva en busca del castigo debido. ${ }^{17}$

La violación de los derechos humanos durante la dictadura constituye otro ejemplo de que la "gran familia humana" es puro idealismo humanístico. ${ }^{18}$ No existe. Así lo ratifica Frantz Fanon en "The Wretched of the Earth". Este ensayo, además de señalar que el humanismo es un fenómeno europeo ligado al imperialismo, explica que este impone creencias parciales como verdades universales. Consecuentemente, los países del "tercer mundo" deben mirar más allá de los parámetros clásicos y erigir una nueva etapa en el desarrollo del "Hombre". Según Fanon, "the same Europe where they were never done talking of Man, and where they never stopped proclaiming that they were only anxious for the welfare of Man: today we know with what sufferings humanity has paid for every one of the triumphs of the mind" (23). Tan sólo pensando en Facundo: civilización y barbarie de Domingo Faustino Sarmiento, fácilmente se nota que la Argentina es uno de los países latinoamericanos que, sin duda alguna, ha tomado a Europa y al mundo occidental como modelo absoluto. Al tener en cuenta que las dictaduras en América Latina surgen como respuesta al miedo de que sus países se vuelquen a un sistema comunista durante

habían participado en el genocidio de ciudadanos habían seguido órdenes de sus superiores, por lo cual quedaban absueltos de todo cargo. A su vez, la ley de punto final exigía la paralización de todo proceso judicial en contra de aquellos que habían participado en la tortura, secuestro y desaparición de personas durante la dictadura militar.

17 H.I.J.O.S. (Hijos por la identidad y la justicia contra el olvido y el silencio) es una organización que lucha por los derechos humanos y pretende mantener la memoria histórica para que no se vuelvan a cometer los errores del pasado. También, la asociación busca hacer justicia para reivindicar aquellos que fueron privados de sus derechos humanos y castigar a los perpetradores. En cuanto a los "escraches", en The Archive and the Repertoire, Diane Taylor explica que estos consisten en "street signs that incorporate the photograph to mark the distance to a perpetrator's home. When they reach their destination, they paint the repressor's name and crimes in yellow paint on the sidewalk in front of the building" (165). Asimismo, artistas plásticos diseñan grafitis y mapas sociohistóricos alternativos que colocan en distintas partes de la ciudad, como por ejemplo "Usted está aquí, a trescientos metros de un campo de concentración" (168).

18 En "The Great Family of Man", Roland Barthes señala que la idea de la "gran familia del hombre" es un mito ambiguo que suprime la importancia de la historia cultural y política, como si fueran factores que no afectan al individuo. Para Barthes, es imposible hablar de una esencia humana invariable. Según Barthes

this myth of the human 'condition' rests on a very old mystification, which always consists in placing Nature at the bottom of History. Any classic humanism postulates that in scratching the history of men a little, the relativity of their institutions or the superficial diversity of their skins (but why not ask the parents of Emmet Till, the young Negro assassinated by the Whites what they think of the Great family of Man?), one very quickly reaches the solid rock of a universal human nature. (101) 
El poshumanismo apocalíptico en la novela negra argentina contemporánea: Ciudad santa y 77 / Osvaldo Di Paolo

la Guerra Fría, se construye la atroz excusa de que, a toda costa, debe prevalecer el exterminio de ideas izquierdistas para el bien común. Esta ideología lleva a los militares de alto rango a perpetrar atrocidades en contra de presuntos grupos de resistencia. Así como Fanon reconoce que Europa es culpable de la destrucción y del sufrimiento de gran parte de la humanidad, para beneficiar a unos pocos, en la Argentina, el supuesto bienestar y futuro del país que imagina el grupo en el poder, requiere la aniquilación de toda idea que no fuese de derecha.

La novela de Saccomanno es una forma de recapacitar sobre la propuesta de Fanon de "rehumanizar a la humanidad". Para el crítico, el tercer mundo debe comenzar una nueva historia del Hombre, ya que la europea está compuesta de crímenes

of which the most horrible was committed in the heart of man, and consisted of the pathological tearing apart of his functions and the crumbling away of his unity. And in the framework of the collectivity there were the differentiations, the stratification and the bloodthirsty tensions... and above all the bloodless genocide which consisted in the setting aside of fifteen thousand millions of men. (25)

En el caso específico de la Argentina, durante la problemática de la Guerra Fría, el llamado a reconsiderar el proceso de deshumanización proveniente de la historia de los países más poderosos no tiene cabida. El país se alinea con el bloque capitalista mundial liderado por los Estados Unidos y, durante la década de los años 70 , el genocidio reaparece en el Tercer Mundo, en el mismo lugar donde Fanon pide que se reconsidere el proceder del hombre.

En la última parte de la novela, el profesor, narrador de la historia, recalca las razones por las cuales se animó a escribir estos sucesos vividos. Su intención es "dejar abierta la tranquera de esta historia para los que quieran entrarle" (Saccomanno 271). Gómez quiere que lo que pasó más de treinta años atrás, no se olvide fácilmente. Es necesario mantener la memoria viva para no cometer los mismos errores, porque, según él, "no se le puede rajar a la historia. Nadie puede hacerse el otario por más que se lo proponga" (269). El profesor narra los hechos "para el bien de todos" (271) y aboga por un cambio en el futuro de la historia del hombre. Él contribuyó con su granito de arena combatiendo el aniquilamiento de sus conciudadanos y reconoce que "mi vida entonces había tenido un sentido. Poner en un taxi a una alumna, darle cobijo a una piba embarazada" (270). Todos esos actos pequeños, habían sido 
realizados para proteger a sus conocidos del genocidio y de la deshumanización gubernamental de ese entonces. Por esta razón, no se va del país. Al comienzo de la novela, lo primero que se pregunta es "por qué no me rajaba". Gómez piensa en voz alta y admite que quizás porque el miedo lo paralizaba, pero que esa era solamente una de las posibles explicaciones y le pide al lector que escuche su relato. Recién al final de la novela, el profesor revela que su misión era proteger a quienes tenían agallas de responsabilidad civil -alumnos y conocidos.

Para aquellos que sufrieron la represión del estado durante el gobierno militar, esos años de miedo, incertidumbre, secuestros, torturas y asesinatos se semejaban a tiempos apocalípticos. El profesor revela que, en el 77, "el terror y la pobreza estaban en todas partes...imposible no verlos, no sentirlos". Además de difundir el peligro que los acechaba, Gómez, a su vez, señala que "Dios, si alguna vez pudo existir, había muerto. Más valía pedirle socorro a los charlatanes que la iban de milagreros. La Difunta Correa o Pancho Sierra ofrecían más esperanzas" (15). ${ }^{19}$ El profesor ha perdido su fe en Dios. Del mismo modo que la iglesia de Éfeso. Según lo que describe el apóstol Juan en Apocalipsis, los habitantes de la ciudad han dejado de creer en Dios: "pero tengo contra ti, que has dejado tu primer amor" (2:4). Sobre este tema, en su análisis sobre el texto bíblico del apocalipsis, John McArthur explica que los que no creen en Dios no pueden entender la dimensión espiritual que los rodea, o interpretar las realidades futuras (29).

En busca de respuestas, el profesor se vuelca a otras creencias. Gómez decide consultar a un vidente, el Doktor Joseph Lutz, quien le dice que la energía cósmica lo ha llevado hasta él, ya que es un mentalista con "avidez de conocimiento" en "los asuntos del misterio cósmico" (Saccomanno 22). El protagonista de la novela quiere llegar a entender la horrenda realidad que lo circunda, ya que es testigo de abusos que se cometen en contra de los derechos humanos. El vidente le confiesa que lo que está pasando en la Argentina es "el Gran Daño y no es nada nuevo. Es parte

19 A Pancho Sierra (1831-1891) se lo conocía como al gaucho santo de Pergamino. En Cultos y canonizaciones populares de Argentina, Félix Coluccio explica que tenía "poderes excepcionales" y que todavía se lo venera en su tumba, ya que sus poderes no se acabaron con su muerte (98-100). Sobre La Difunta Correa, Roque Pichetto aclara que "la difusión de sus milagros ya tradicionales se ha extendido por todo San Juan: los poetas y cantores populares le dedican sus coplas y canciones, los hombres de campo le piden protección para sus cosechas, los arrieros, con quienes tiene una deuda, la consideran su protectora, hacen sus peligrosos viajes a través de las serranías y quebradas bajo su amparo, las madres que por su debilidad carecen del necesario alimento para sus pequeñuelos, elevan sus oraciones fervientes a ella para que nutra sus pechos escuálidos" (95). 
El poshumanismo apocalíptico en la novela negra argentina contemporánea: Ciudad santa y 77 / Osvaldo Di Paolo

de los truenos que anuncian los cambios catastróficos que se le avecinan al planeta" y agrega que "ese Gran Daño ya está ocurriendo en el país" (42). Es, en realidad, el principio del fin, como si se manifestara uno de los sellos que se abre y esparce destrucción y violencia. El apóstol Juan escribe que, cuando se abrió el cuarto sello, la voz le dijo que "le fue dada potestad sobre la cuarta parte de la tierra, para matar con espada, con hambre, con mortandad, y con las fieras de la tierra" (6:8). Estos son los síntomas que atestigua el profesor.

Para el Doktor, el genocidio es una manifestación de que el final está cerca y le confiesa a Gómez que para "los chupacirios del poder, la juventud encarna los designios del Anticristo. Los militares son la Santa Inquisición. Para ellos, la tortura es el exorcismo" (Saccomanno 42). De manera irónica, el vidente está rectificando la lucha de la guerrilla en contra de los militares, quienes a pesar de que ellos tienen la convicción de estar del lado de Dios, es una falacia. Muchos pasajes bíblicos advierten de los falsos profetas. Por ejemplo, en el texto bíblico de Jeremías, el Señor replica que "falsamente profetizan los profetas en mi nombre, no los envié, ni les hablé, visión mentirosa, adivinación, vanidad y engaño de su corazón os profetizan" (14:14).

Son los mismos militares los que justifican sus asesinatos en pos de paz y seguridad, y quienes abogan por una doctrina de seguridad nacional. En La doctrina militar de seguridad nacional, Roberto Calvo señala que, para "los militares chilenos, la seguridad nacional es la estructuralización de las potencialidades de un país, de manera que su desarrollo sea factible con el completo dominio de su soberanía e independencia tanto interna como externa" (66). Asimismo, para el Gral. O. G. Villegas, "no puede haber seguridad sin desarrollo, como desarrollo sin seguridad" (8).$^{20} \mathrm{Es}$ decir, que con la excusa de la necesidad de progreso, paz y estabilidad para la construcción de un futuro nacional, aquellos en el poder justifican el genocidio existente. Lo mismo ocurre con Adolf Hitler, quien en su libro Mi lucha promete ser un hombre pacífico, llevando a Francia y a Inglaterra a creer en su palabra (McArthur 183).

El mismo apocalipsis revela la falsa paz del primer sello.. ${ }^{21}$ Algunos identifican al jinete como al Anticristo, quien engaña con la instauración de una paz engañosa, pero que es seguida por muerte, hambre y guerra (184).

20 Ver "Seguridad, política y estrategia" en Temas Militares Vol.4, 1968.

21 El apóstol Juan escribe que vio "un caballo blanco y el que lo montaba tenía un arco y le fue dada una corona, y salió venciendo, y para vencer" (6:1-2).

$+2$


Frente a esta incertidumbre y falsas pretensiones del gobierno militar, varios personajes de la novela van en busca de otras formas de espiritualidad. La madre de un alumno del profesor va a ver a una vidente en busca de noticias sobre el paradero de su hijo desaparecido. El narrador puntualiza que "la brujería, el tarot, los astros: cualquier manganeta es válida para devolverle a los padres la esperanza perdida" (Saccomanno 202). Mientras que el vidente que consulta el profesor le dice que los militares piensan que los guerrilleros son el Anticristo, la vidente que visita la mujer enfatiza que, si bien los jóvenes son idealistas, la época del 77 es mala para los espirituales, porque "hay magos negros gobernando. Poderosos son" (202). También, al irse del consultorio de la vidente, la secretaria les dice a los padres del muchacho que "muchos otros vienen en busca de respuestas, pero que la magia de los magos negros es tan poderosa que no le permiten ver nada a la vidente" (206). Es claro que la intención del narrador y de los videntes es presentar a los mismos militares como fuerzas negativas, apocalípticas y responsables del genocidio.

No solamente los padres de desaparecidos se refugian en otras formas de espiritualidad, sino que Gómez también conversa con su amigo Bodhi Darma sobre El círculo hermético, la correspondencia entre Hermann Hesse y C.G. Jung. El muchacho le lee una cita de Hesse, afirmando que "nada sucede casualmente...éste es el círculo hermético (25). Bodhi insinúa que el genocidio y el horror de la dictadura son parte de un plan. Siguiendo el texto del apóstol Juan, se podría pensar que la violencia de Estado y sus consecuencias son un malestar más dentro del espectro apocalíptico que enfrenta el mundo. A su vez, la correspondencia que incluye Miguel Serrano en C.G. Jung and Hermann Hesse: A Record of Two Friendships revela que el profesor podría estar explorando las dos tendencias que se manifiestan en Narcissus and Golmund y Siddharta de Hesse. Como ya se mencionó anteriormente, Gómez reconoce que de manera indirecta, ayudaba a conocidos y alumnos que se rebelaban en contra de la dictadura y que los admiraba, porque él solamente contemplaba el horror, al caminar por la ciudad durante la noche. Serrano explica que los personajes de Hesse-Narciso y Golmundo- representan dos tendencias fundamentales en el hombre: "contemplation and action" (7). De manera similar, Siddharta y Govinda representan características opuestas de devoción y rebelión.

A primera vista, el profesor parece ser mero testigo del genocidio por su incapacidad de tomar acción y sumarse a la rebelión que Esteban y otros conocidos están llevando a cabo. El texto bíblico del apocalipsis 
El poshumanismo apocalíptico en la novela negra argentina contemporánea: Ciudad santa y 77 / Osvaldo Di Paolo

no da lugar a duda o posiciones intermedias. Uno se alía al "bien" o se identifica con el "mal". El profesor, de forma indirecta, se une a la causa para resistir la destrucción de los "magos negros". A su vez, la escritura de su testimonio lo purga de la culpa de no haber expresado más firmemente sus convicciones, y es por medio de la escritura que entiende que no se fue del país, porque su misión era asistir y proteger a aquellos que eran perseguidos.

\section{Conclusión}

Las novelas previamente analizadas permiten marcar ciertas tendencias del género negro del nuevo milenio. En primer lugar, ninguna de ellas presenta la figura de un detective propiamente dicho. A los detectives de Ciudad santa no les conviene resolver los crímenes que se cometen, ya que ellos están involucrados en secuestros, asesinatos y tráfico de drogas. En 77, es un profesor de secundaria el que, preocupado por el bienestar de sus alumnos y otros jóvenes, indaga sobre el paradero de estos muchachos y, a su vez, narra sobre la violencia y el terror que se vive durante 1977. Los seudo-detectives son parte del desencanto y les faltan esperanzas como al resto de la población. Mientras que el detective clásico busca la verdad, el investigador del nuevo milenio se mueve en el caos, no puede detener el inevitable fin y se convierte en una víctima de la sinrazón que reina en Buenos Aires.

En estos "textos negros", los crímenes y el comportamiento poshumanista de los protagonistas demuestran la descohesión social y la falta de raciocinio en las acciones cotidianas de los personajes, como si estuvieran fingiendo ser seres humanos y carecieran de lógica, un distintivo primordial entre lo humano y lo no-humano. El proceder de estos individuos se encuentra ligado a las ansias de codicia, riqueza y poder -elementos carentes en el resto de la naturaleza-, dejando de lado todo código ético y la búsqueda de un progreso colectivo. Es imposible hablar de "la gran familia del hombre". En cambio, se acentúan las diferencias étnicas, socioeconómicas y espaciales en el seno social. Pareciera que la Argentina tiene compenetrada una violencia proveniente del tráfico de drogas, la prostitución, el rapto de turistas, secuelas de crueles gobiernos de facto, la corrupción de las fuerzas de la ley y los funcionarios del gobierno. La idea del humanismo es una ficción europea ligada al imperialismo, que trae consecuencias nefastas como la tortura, el miedo, la inseguridad, el secuestro y el asesinato provenientes del terrorismo de Estado. 
Buenos Aires es una ciudad venida a menos y sin salvación. La destrucción y el caos sobrepasan toda esperanza de revertir la situación. La posibilidad de regeneración es escasa. En Ciudad Santa, únicamente un loco reconoce esta situación y se refugia en un parque de temática religiosa, en busca de redención. A su vez, los personajes se identifican con prácticas espirituales alternativas -ocultismo, profecías, astrología hermética, I Ching, videntes y hechizos. Lo que es más, la ciudad misma segrega un sentido de melancolía sin esperanza, típico del apocalipsis laico y posmoderno. Reina la inestabilidad, el genocidio y la muerte a borbotones. En estas novelas, el apocalipsis es más bien un quejido que una explosión y se centra en una visión de un fin indefinido y pesimista, sin expectativas de un futuro brillante, librándose una constante batalla cósmica entre fuerzas opuestas.

\section{Bibliografía}

Badmington, Neil. "Approaching Posthumanism". Posthumanism. Neil Badmington Ed. New York: Palgrave, 2000.

"Posthumanism". The Routledge Companion to Literature and Science. Eds. Bruce Clarke y Manuela Rossini. New York: Routledge, 2011. 374-84.

Bielous, Silvia. Tramitando el pasado: violaciones de los derechos humanos y agendas gubernamentales en casos latinoamericanos. México D.F.: CLASCO, 2010.

“Bolivianos 'pobres' son los más discriminados en la Argentina según la Unicef". El Día. 16 de julio, 2011.1.

Carbajal, Emilio. "Apocalipsis: la angustia del fin del mundo o la esperanza de mil años de felicidad". Ritos y creencias del nuevo milenio. México D.F.: ALER, 2000. 83-101.

Centanino, Horacio. La dictadura (1973-1983): reflexiones y relatos. Buenos Aires: Lulu, 2011.

Coluccio, Félix. Cultos y canonizaciones populares de Argentina. Buenos Aires: Ediciones del Sol, 2007.

Delumeau, Jean. "El Apocalipsis recreado". El fin de los tiempos. Ed. JeanClaude Carrière. Barcelona: Círculo de Lectores, 2000. 69-127.

Di Paolo, Osvaldo. Cadáveres en el armario: el policial palimpséstico en la literatura argentina contemporánea. Buenos Aires: Teseo, 2011. 
El poshumanismo apocalíptico en la novela negra argentina contemporánea: Ciudad santa y

77 / Osvaldo Di Paolo

Ederly, Jorge. "De Guyana a Uganda: suicidios colectivos rituales". Ritos y creencias del Nuevo milenio. México D.F.: ALER, 2000. $117-81$.

Edinger, George. Archetype of the Apocalypse: Divine Vengeance, Terrorism, and the End of the World. Chicago: Open Court, 1992.

Fanon, Frantz. "The Wretched of the Earth". Posthumanism. Ed. Neil Badmington Ed. New York: Palgrave, 2000.

Gale Robinson, Wendy. "Heaven's Gate: The End?". The Journal of ComputerMediated Communication 3 (1997): 1-12.

Halpern, Paul. Countdown to Apocalypse: A Scientific Exploration of the End of the World. Cambridge: Perseus, 2000.

Hahn, Scott. Lamb's Supper: The Mass as Heaven on Earth. New York: Doubleday, 1999.

Lafforgue, Jorge. Asesinos de papel. Buenos Aires: Calicanto, 1977.

Lebrato Martínez, Daniel. "Notas sobre la novela negra". Revista de Bachillerato 23 (1982): 120-30.

Lefebvre, Henri. La revolución urbana. Madrid: Alianza, 1976.

McArthur, John. Comentario del nuevo testamento: Apocalipsis. Buenos Aires: Portavoz, 2010.

Miranda Matos, Enid. "Sectas Destructivas Terrorismo Religioso". Escenarios sectarios peligrosos. Aug. $2004<w w w . v i c t i m a s e c t a s$. com/Terrorismo/Orden Templo solar.htlm>. Web. 1 Oct. 2011.

Morales Solá, Joaquín. "Narcotráfico: el país sigue los pasos de Colombia y México". La Nación. 1 de marzo, 2001. 1.

Nelson, Thomas. Holly Bible Catholic Edition: The New Revised Standard Version. Ed. Thomas Nelson. Nashville: Imprimatur, 1993.

Orsi, Guillermo. Ciudad santa. Córdoba, Argentina: Almuzara, 2009.

Pichetto, Roque Jacinto. Brochazos mendocinos; relatos históricos, tradiciones cuyanas, cuadros de Mendoza, anécdotas mendocinas. Mendoza: Ediciones D'Accurzio, 1994.

Saccomanno, Guillermo. 77. Buenos Aires: Planeta, 2008.

Sanz, Cristina. Poli Armentaro: un crimen perfecto. Buenos Aires: Cien, 2003.

$+28$


Serrano, Miguel. C.G. Jung and Hermann Hesse: A Record of Two Friendships. London: Routledge, 1966.

Starr, Martin. Unknown God: W.T. Smith and the Thelemites. Bowlingbrook, Illinois: Teitan, 2003.

Taylor, Diane. The Archive and the Repertoire: Performing Cultural Memory in the Americas. Durham: Duke UP, 2003.

Villegas, Osiris Guillermo. "Seguridad, política y estrategia". Temas Militares 4 (1968): 25-49. 